\title{
"The Beginning Is the Most Important Part of the Work": Discovering Professional Identity and Purpose at the 2012 RBMS Preconference
}

The 2012 RBMS PreConference was my first experience participating in a professional, rather than academic, conference; as someone relatively new to the Section, and moreover to the world of rare books and manuscripts generally, naturally I was not entirely sure what to expect. At the same time I did have in mind a certain idea of what I hoped to gain from the experience, and looking back I think that for the most part I realized most of these more concrete goals. However, the greatest benefits for me, as so often seems to happen, were in hindsight also those that were the most serendipitous - meeting fellow members (in fact, my colleagues, as I may now think of them!), learning about their work, and finally gaining a greatly broadened understanding of our larger shared mission in special collections.

First, I must say that I took away so much valuable practical knowledge from a few events in particular: "Special Collections for Digital Humanities"; "Metadata for Digital Projects"; the "Discovery: Linked Open Data" plenary and succeeding linked open data seminar; and "The Future of Rare Materials Cataloging Standards." I found that all these talks, in very different yet highly complementary ways, helped me to think about potential futures for representational practices in special collections, while at the same time broadening my base of practical understanding on a more fundamental level. The linked open data plenary, with Jon Voss and Michael Panzer, I found especially inspiring - both speakers stressed the power of combinatory principles of description and representation, while Panzer's examples in particular, which situated linked data within familiar cataloging contexts, left a great impression on me regarding how one might most productively conceptualize the proper forms and roles that the ideal record could take. I have now revised my understanding of the true value of metadata and linked data beyond their immediate applications, coming to understand linked data as the next frontier in representation, an approach that doesn't supersede but rather maximizes the textual record, creating a representational context that may be as expansive and flexible as desired by either the cataloger (how extensive a frame of semantic data will the record contain?) or the user (how far does one wish to pursue linked elements within that 
frame?). This notion of a truly combinatory flexibility within records is revelatory to me, and I continue to follow its development as the future of representation.

Next, I would like to speak to the value of the preconference for professional development. Though initially I was focused on the topical content of events in accordance to how closely they aligned with my own nascent interests, my actual experience would soon reveal that each event was invariably enhanced beyond measure by the presence of colleagues and senior professionals, all of whom bring to RBMS an excitingly diverse array of backgrounds, experiences, and interests. I quickly came to think of every convocation, from plenaries to incidental conversation, as fortuitous opportunities to not simply make passive receipt of new ideas, but also to actively generate these. I really enjoyed this give-and-take, which I discovered at every event and which ultimately was one of my favorite parts of the conference. The members of RBMS, with their incredible collective body of experience and expertise, truly are the heart and soul of the organization, and interacting with the amazing people I met throughout the preconference led me to the important understanding that my fellow special collections professionals are my single greatest and most valuable resource and likely always will be. At the "Selling Books to Rare Book Librarians” seminar, moderated by Terry Belanger, several attendees spoke, in often very personal fashion, about their experiences both as special-collections librarians as well as private collectors, and about highly specific issues in today's collecting climate (for example, the future of en bloc collecting, as well as the shifts in perceived value from provenance and association elements to sociocultural importance), which I cannot imagine I should ever have had the privilege of hearing firsthand elsewhere. In fact, I think this seminar may have been a turning point for me: for the first time, I was part of an entire roomful of people (many of whose names I recognized thanks to their distinguished contributions to our profession) who shared my enthusiasm not only for rare materials but also for the obscurer niceties of collecting culture; to recognize a bit of myself and my own bibliographical obsessions in the midst of such venerability and accumulated wisdom felt like a true initiation into this milieu, one that I can best describe only as inspiring: looking back, I feel that moment was a decisive beginning, from the best possible place, from which the next natural step was but to go forth with purposeful enthusiasm.

Finally, I would like to expand upon this notion of inspiration and speak to the unique philosophical education I gained at the preconference this year. The opening and closing plenaries were perfect complements: thanks to Matthew Kirschenbaum and Bethany Nowviskie, for the first time I was able to properly conceptualize the digital object as something of value in itself, rather than only in lieu of its surrogacy for some other, more privileged "physical" object. This realization truly 
was enlightenment - it has remained with me ever since and has greatly expanded my understanding of what the proper province of special collections might be, of the infinitely varied field of collectible artifacts, and of the amazing things that we are already accomplishing beyond the realm of the traditional physical imperative. It was quite exciting to realize all the dynamic attitudes toward the object that are influencing the course of the profession right now. Similarly, the closing plenary, featuring Michael F. Suarez and Johanna Drucker, was equally revelatory, leading me full circle to this important realization, which has never been far from my mind since: the library is not necessarily about the object, but rather about the individual's felicitous and highly personal confrontation with it. By extension, then, our task is not simply to reposit and curate the object as lone, discrete artifact, whatever form it may take, but rather to enable access to a multiplicity of individual encounters with a multiplicity of individual objects. It is here that our traditional emphasis on physicality intersects with new forms of representation and access, the latter prescribed in accordance with what Drucker termed "artifactual contextualization," with its infinite number of dimensions_-social, bibliographical, cultural, historical—whose emphasis will inevitably vary from subject to subject as well as from object to object. Our challenge now is to (continue to) find flexible means of variously accommodating the diverse contextual demands of each unique user encounter.

After San Diego, I returned to my curatorial internship at The Lilly Library and, a couple months later, took up a full-time, special-projects position within the cataloging department. Cataloging has always particularly attracted me, alongside curatorial work: in terms of purpose they seem to me twinned, for in my view each are very largely about both how we regard the object and how we may construct and manipulate its representations to differently color and frame that regard, in accordance with variant contexts of apprehension and use. In discussions with my colleagues at the Lilly, I have come to conceive even of traditional rare-books cataloging not as prescriptive application of a limited set of descriptive fields but rather as a potentially more elastic and versatile kind of language: cataloging may be as expressive as it is descriptive, capable of realizing different shadings of emphasis which allow for greatly enhanced representational relevance. I am doubtful that my daily work should be grounded in quite so strong a sense of philosophical conviction and purpose, were it not for my experiences last summer.

In short, I am immensely grateful for the knowledge I gained at the preconference. Per Oliver Wendell Holmes, Sr., "A man's mind stretched to a new idea never goes back to its original dimensions"; not only have my daily practical understanding and sense of professional identity been immeasurably augmented, in fact my entire philosophical motivation in my engagement with rare books has also been refined 
and enlarged: I now think not simply in terms of the object, but above all in terms of what it must variously represent to different individual users, all of whom will necessarily encounter it differently. Consequently I now have a renewed sense of the primacy of the user to our work, which in turn contributes to my sense that I pursue my own work not only out of a personal enthusiasm and love for rare materials, but toward the greater end of sharing all the richness of our collections, and thereby (I hope) of leading others to discover their own such enthusiasms. I am so endlessly thankful for the opportunity to realize all these new forms of knowledge; moreover, I look forward to continuing this work within RBMS and ACRL, not only at future preconferences, but year-round, and, certainly, for many years of meaningful work to come!

\section{CALADEX}

LOGISTICS

PERSONALISED TRANSPORTATION MANAGEMENT specializing in fine book packing and shipping On-site packing by our qualified team Door to door transportation from any USA point
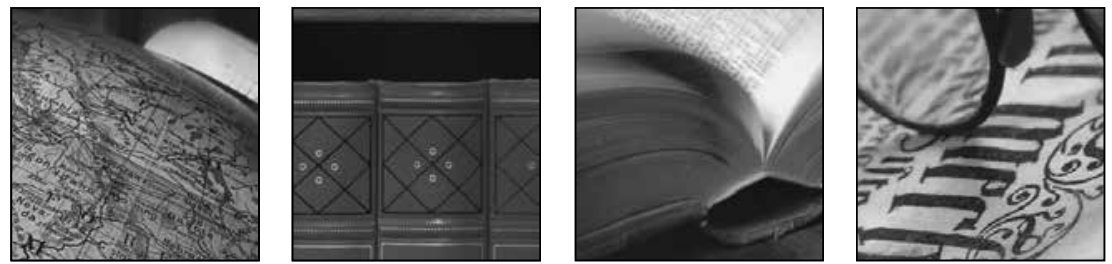

For information on Caladex LLC and the services we offer, please contact us at:

USA \& CANADA

Tel:

Fax:
8006434315

7182334159
UK

Tel:

Fax:
02079938511

02076813435

Email: info@caladex.com • www.caladex.com 